\title{
A METHOD FOR PREDICTING THE CONSOLIDATED UNDRAINED BEARING CAPACITY OF SHALLOW FOUNDATIONS
}

Published in Géotechnique, 64, No. 3, 215-225, http://dx.doi.org/10.1680/geot. 13.P.101

\section{Susan M. GOURVENEC (corresponding author)}

Centre for Offshore Foundation Systems - M053

University of Western Australia

35 Stirling Highway, Crawley, Perth, WA 6009, Australia

Tel: +61 86488 3995, Fax: +61 864881044

Email: susan.gourvenec@uwa.edu.au

\section{Cristina VULPE}

Centre for Offshore Foundation Systems

Email: cristina.vulpe@uwa.edu.au

\section{Tejas G. MURTHY}

Indian Institute of Science, Bangalore - 560012, India

Email: tejas@civil.iisc.ernet.in

* Formerly Research Associate, COFS, University of Western Australia

No. of words: 5474

No. of tables: 2

No. of figures: 15 


\begin{abstract}
:
The effect of consolidation on the undrained bearing capacity of rough and smooth, strip and circular surface foundations is investigated, examining the influence of the magnitude and duration of an applied preload and the initial over consolidation ratio of the deposit. The investigation comprised small strain finite element analysis with the soil response being represented by Modified Cam Clay. The results are distilled into dimensionless and generalised forms, from which simple trends emerge. Based on these results, a simple method for predicting the consolidated undrained bearing capacity is proposed.
\end{abstract}

Key words: Shallow foundations, consolidation, settlement, bearing capacity 


\section{INTRODUCTION}

The bearing capacity of a shallow foundation on fine-grained soil will generally be enhanced by consolidation of the surrounding soil under the weight of the foundation. Consolidation will occur as result of in-service foundation loads or may be accelerated by preloading the foundation prior to service. Any increase in bearing capacity is a consequence of the increase in shear strength of the soil. The increase in shear strength is non-uniform across the zone of influence, and is related to the stress change within the pressure bulb developed in the soil due to the application of the foundation load or preload.

Determination of the consolidated undrained bearing capacity of a shallow foundation is relevant to various civil and offshore engineering scenarios including (i) reuse of existing foundations for new structures following demolition of an existing structure, (ii) for additional loads to be added to existing foundations, (iii) preloading of jack-up rigs to set up the in-service general load capacity of spudcan foundations, (iv) soil improvement to enhance the bearing capacity of soft clays, and (v) predicting the increase in factor of safety of a foundation over the lifetime of the structure (which in turn diminishes the annual probability of failure under the governing design loading event).

Consolidation beneath strip and circular surface and shallowly embedded foundations on an elastic medium has been considered previously (e.g. Butterfield and Banerjee 1971, Davis and Poulos 1972, Booker and Small 1986, Gourvenec and Randolph 2009, 2010). Coupling of consolidation and soil yielding, and assessment of the consolidated undrained bearing capacity of shallow foundations has received less attention. 
Bransby (2002) studied the effect of preloading on the undrained bearing capacity of a rough-based surface strip foundation on a normally consolidated and heavily over consolidated soil profile through coupled consolidation small strain finite element analysis. The results show greater gains in bearing capacity in the normally consolidated deposit than the heavily over consolidated deposit and a greater proportional gain in the consolidated undrained lateral capacity compared to the vertical capacity. This is because the lateral failure mechanism is predominantly within the localised zone of soil strength improvement close to the foundation. Bransby proposed the use of a hardening law to link the gain in undrained bearing capacity to the accumulating foundation settlements.

The effect of preloading on the undrained vertical bearing capacity of smooth and rough-based strip foundations on deposits with a range of over consolidation ratios (OCR) has also been addressed with small strain finite element analysis (Zdravkovic et al. 2003). The results indicate that the increase in capacity reduces with increasing OCR, reflecting the Bransby (2002) results.

These numerical studies considered only the bearing capacity following full primary consolidation, without consideration of the gain in strength for lesser time periods that may be of more practical relevance. They are also limited to plane strain conditions.

Lehane and Jardine (2003) report a pair of field tests considering the immediate and consolidated undrained vertical bearing capacity of a $2.5 \mathrm{~m}$ square foundation embedded by $0.9 \mathrm{~m}$ into a lightly over consolidated clayey-silt, addressing the bearing capacity gain due to preloading. An 11 year period of consolidation led to a $48 \%$ gain in undrained vertical bearing capacity following preloading at approximately two-thirds of 
the immediate undrained capacity. This was noted by the authors of the study to be more than twice that expected based on the FEA predictions reported by Zdravkovic et al. (2003) for similar soil conditions.

Centrifuge model tests reported by Lehane and Gaudin (2005) on $1 \mathrm{~m}$ and 2 m square foundations, embedded to a depth of $1.25 \mathrm{~m}$ in an over consolidated kaolin indicate a greater gain in bearing capacity than predicted by either the finite element analysis of Zdravkovic et al. (2003) or the field test described above (Lehane and Jardine 2003). The predictions from the centrifuge tests are more consistent with the finite element predictions for a normally consolidated soil profile $(\mathrm{OCR}=1)$ despite the centrifuge tests representing a considerably higher OCR $(4-8)$.

Figure 1 graphically represents these calculated or measured gains in undrained vertical bearing capacity as a function of preload level for complete or near-complete primary consolidation. It should be borne in mind that the studies represent independent investigations with varying boundary conditions including foundation shape, embedment ratio, interface roughness, material parameters, stress state and constitutive response and as such, the results should not necessarily bear semblance with each other. Directly comparable input or output quantities are not presented across the studies, which further hampers comparison of the results. Nonetheless, it is clear that significant potential gains in the bearing capacity of a shallow foundation can be achieved as a result of consolidation. There is clearly scope for increased understanding of the generalised behaviour which motivated this study.

The study reported in this paper examines systematically the effect of the magnitude and duration of an applied preload or in-service foundation load on the gain in 
undrained bearing capacity, considering smooth and rough-based, strip and circular foundations resting on the surface of deposits with a range of over consolidation ratio. The study used small strain finite element analysis with a commercially available finite element software and a classical critical state soil model to couple the effects of consolidation and strength gain. The results are generalised using a new approach that is intended to support simple design calculations.

\section{FINITE ELEMENT MODEL}

\section{Foundation geometry}

Rigid, surface strip and circular foundations with either a rough or smooth interface with the underlying soil mass were considered. The foundations were of unit width (i.e. $1 \mathrm{~m})$, but only dimensionless results are considered.

\section{Soil conditions and material parameters}

Soft to stiff clay conditions were represented, described by an initial over consolidation ratio (OCR) taken as $\sigma_{\mathrm{vc}}^{\prime} / \sigma_{\mathrm{v} 0}^{\prime}=1,2,4$ and 10 , constant with depth. The pre-yield soil response was represented with a poro-elastic response and post-yield plasticity was based on the Modified Cam Clay constitutive model. The parameters describing the soil material modelled in this study are given in Table 1 . The model parameters are derived from element testing programmes on kaolin clay reported by Stewart (1992) and Acosta-Martinez and Gourvenec (2006). However, since the results are generalised in terms of only the OCR and the normalised bearing capacity, they are not only applicable to these adopted soil parameters. 


\section{Finite element mesh}

Plane strain and axisymmetric finite element meshes were used to model the strip and circular foundations respectively. A schematic of the adopted mesh configuration is shown in Figure 2 and an example of a finite element mesh in Figure 3. The mesh boundaries were placed sufficiently remote from the foundation to ensure no boundary effects on the foundation response. A mesh half-width and depth of 10 times the foundation breadth or diameter was adopted. Vertical mesh boundaries were constrained from horizontal displacement and horizontal boundaries were constrained from vertical and horizontal displacement. The free surface of the mesh either side of the foundation was prescribed as a free drainage boundary. The other external mesh boundaries and the foundation were represented as impermeable boundaries.

Similar mesh discretisation was adopted in the plane strain and axisymmetric models. Mesh sensitivity studies were carried out to identify an optimum mesh, which resulted in approximately 5,000 elements in the plane strain mesh and 2,500 elements in the axisymmetric mesh.

The foundation was represented as a rigid body with a single load reference point located at the centre of the foundation. The soil was represented by second order reduced integration stress-pore fluid consolidation continuum elements.

\section{Scope and loading methods}

The in situ, i.e. unconsolidated, undrained uniaxial vertical bearing capacity, $\mathrm{v}_{\mathrm{u}}$, (defined as the applied vertical force per unit area of foundation) was determined for each foundation shape, interface condition and OCR considered. Subsequent analyses 
involved preloading the foundation by an amount defined as a proportion of $\mathrm{v}_{\mathrm{u}}$, i.e. $\mathrm{v}_{\mathrm{p}} / \mathrm{v}_{\mathrm{u}}$, followed by a period of consolidation after which a vertical displacement was applied to cause undrained failure, giving the consolidated undrained vertical bearing capacity, $\mathrm{V}_{\mathrm{u}, \text { cons. }}$ The first of the consolidation analyses permitted full primary consolidation while subsequent analyses considered intermediate degrees of consolidation.

Each analysis followed the same principal steps; (1) establishment of the in situ stress conditions, (2) preloading of the soil beneath the foundation under $v_{p}$, (3) a consolidation period, and (4) undrained uniaxial vertical bearing failure, mobilising $\mathrm{Vu}$,cons.

The in situ state of the soil was established by allowing the soil to reach equilibrium under the assigned unit self-weight, $\gamma$, and the applied surface surcharge. A nominal surcharge equal to $1 \mathrm{~m}$ overburden of soil was applied in all analyses to prevent a zero stress state at the mudline. Over consolidation, if required, was achieved by applying a multiplier to the body forces equal to the desired OCR. For example, in order to achieve a soil with OCR $=4$, a surcharge 4 times the in situ value was applied and the body forces were increased to $4 \gamma$. A period of consolidation was then prescribed sufficient to enable dissipation of all excess pore pressures (via the drainage boundary along the free surface of the soil). Following complete primary consolidation, i.e. when all the excess pore water pressure had dissipated, the surcharge was reduced to the in situ value (equivalent to $1 \mathrm{~m}$ of overburden) and the body forces were reassigned the original unit weight. A further period of consolidation - during which swelling occurred - was prescribed in order to achieve the desired in situ stress condition and OCR. This 
procedure for over consolidation resulted in a constant value of OCR with depth. Although a constant OCR with depth is not representative of the conditions created by mechanical over-consolidation through deposition and erosion, this method provides a simple basis for investigating systematically the influence of OCR.

Preloading was prescribed in increments of $10 \%$ of the unconsolidated undrained ultimate bearing load, $\mathrm{v}_{\mathrm{u}}$, i.e. $\mathrm{v}_{\mathrm{p}} / \mathrm{v}_{\mathrm{u}}=0.1,0.2,0.3$ etc up to 0.7 , which is a practical maximum in design. The consolidation period for dissipation of the excess pore water pressure developed due to the preload, was prescribed as a proportion of the time for practical completion of the primary consolidation, $\mathrm{T}_{99}$. Intervals corresponding to $\mathrm{T}_{15}$, $\mathrm{T}_{30}, \mathrm{~T}_{50}, \mathrm{~T}_{70}, \mathrm{~T}_{90}$ and $\mathrm{T}_{99}$ were considered i.e. representing the time for $15 \%, 30 \%$, $50 \%, 70 \%, 90 \%$ of full practical primary consolidation to occur. Following the application of preload and the prescribed period of consolidation, the soil was brought to failure under displacement-controlled undrained vertical foundation displacement to identify the consolidated, undrained vertical bearing capacity $\mathrm{v}_{\mathrm{u}, \mathrm{cons}}$.

\section{Limitations of the model}

A constant value of the permeability coefficient was selected in this study. In reality, permeability may vary with effective stress level and voids ratio. However, the accuracy with which the change in permeability with void ratio can be practically assessed should be considered alongside an assessment of the approximation of assuming a constant value of permeability.

Modified Cam Clay models a linear elastic soil response inside the yield surface such that changes in pore pressure result only from changes in mean effective stress (not 
deviatoric stress). As a result, the constitutive model may not exactly replicate the actual stress path during consolidation in over consolidated deposits at stress levels less than the pre-consolidation pressure. For over consolidated deposits under stress levels in excess of the pre-consolidation pressure and normally consolidated deposits (OCR $=1$ ) there is no pure elastic response under loading and pore pressure changes are due to coupled effects of changes in the mean effective and deviatoric stresses.

Modified Cam Clay is best suited to modelling the response of normally consolidated and lightly over consolidated soils. Shear strength can be over predicted under some stress paths for highly over consolidated soil profiles if a Hvorslev surface is not considered on the dry side of the critical state line. With this in mind, this study considered OCR no greater than 10. It should also be borne in mind that potential gains in bearing capacity diminish considerably with increasing OCR, such that minimal gain in bearing capacity is available in heavily over consolidated deposits.

\section{RESULTS}

\section{Validation}

The undrained vertical bearing capacity predicted by the FEA was compared with analytical predictions using the method of characteristics (Martin 2003) to validate the finite element model. In order to make the comparison, the plane strain undrained shear strength, $\mathrm{s}_{\mathrm{u}}$, associated with each OCR for the critical state model with the parameters adopted in this study was calculated from Equation 1 (Potts and Zdravkovic 2000). Plane strain undrained shear strength was selected to represent an average value of the triaxial 
compression, triaxial extension and plane strain stress paths experienced by the elements of soil involved in the bearing capacity failure. The resulting undrained shear strength profiles are shown in Figure

4. $\frac{\mathrm{s}_{\mathrm{u}}}{\sigma_{\mathrm{v}}^{\prime}}=\left[\operatorname{OCRg}(\theta) \cos \theta \frac{\left(1+2 \mathrm{~K}_{0}^{\mathrm{nc}}\right)}{6}\left(1+\mathrm{A}^{2}\right)\right]\left[\frac{2\left(1+2 \mathrm{~K}_{0}^{\mathrm{oc}}\right)}{\left(1+2 \mathrm{~K}_{0}^{\mathrm{nc}}\right) \operatorname{OCR}\left(1+\mathrm{A}^{2}\right)}\right]^{\mathrm{K} / \lambda}$

where

$g(\theta)=\frac{\sin \phi}{\cos \theta+\frac{1}{\sqrt{3}} \sin \theta \sin \phi}$

$\mathrm{A}=\frac{\sqrt{3}\left(1-\mathrm{K}_{0}^{\mathrm{nc}}\right)}{\mathrm{g}\left(-30^{\circ}\right)\left(1+2 \mathrm{~K}_{0}^{\mathrm{nc}}\right)}$

$\mathrm{K}_{0}^{\mathrm{nc}}=1-\sin \phi$

$\mathrm{K}_{0}^{\mathrm{oc}}=\mathrm{K}_{0}^{\mathrm{nc}} \mathrm{OCR}{ }^{\sin \phi}$

$\theta=$ Lode's angle (taken as $0^{\circ}$ for plane strain conditions)

Comparison of results from the finite element analyses with method of characteristics solutions (Martin 2003) showed agreement confirming the adequacy of the model.

\section{Consolidated undrained bearing capacity following full primary consolidation}

Figure 5 shows the gain in bearing capacity resulting from preloading and full primary consolidation, as a function of normalised foundation settlement w/B. Results are shown for the smooth and rough-based strip foundations resting on the normally consolidated deposit $(\mathrm{OCR}=1)$. The gain in bearing capacity with increasing preload is evident, with 
more than $50 \%$ gain in capacity $\left(\mathrm{v}_{\mathrm{u}, \text { cons }} / \mathrm{v}_{\mathrm{u}}>1.5\right)$ achieved for a preload of $70 \%$ of the undrained unconsolidated capacity $\left(\mathrm{v}_{\mathrm{p}} / \mathrm{v}_{\mathrm{u}}=0.7\right)$. The interface roughness did not affect the proportional increase in capacity, although the absolute values of ultimate bearing capacity differ. This phenomenon was observed for the other levels of OCR considered and also for the circular foundation geometry. The independence of the gain in bearing capacity and interface roughness was also apparent from the results presented by Zdravkovic et al. (2003). The subsequent results are therefore equally applicable for smooth or rough-based foundations.

Figure 6 shows the gain in bearing capacity due to preloading and full primary consolidation for strip and circular foundations for each OCR considered. The greatest gains in capacity were achieved in the normally consolidated deposit with approximately $10 \%$ greater gain achieved for the strip foundation compared with the circular foundation. As mentioned above, more than $50 \%$ increase in the bearing capacity of the strip foundation was observed for a preload of $0.7 \mathrm{v}_{\mathrm{u}}$, while maximum gains in bearing capacity of $25 \%, 15 \%$ and $10 \%$ were achieved for the same level of preload and OCRs of 2, 4 and 10 respectively. There was negligible difference in the relative gain for strip and circular foundations at OCR $>1$.

Larger gains in bearing capacity are to be expected in a normally consolidated deposit compared to an over consolidated deposit, since a greater change in void ratio results from a given applied foundation load, leading to a greater increase in the operative shear strength of the soil. Conceptually, the consolidation after preloading of a normally consolidated soil follows a stiffness close to the virgin compression stiffness $\lambda$ compared with an over-consolidated case which is closer to the reloading stiffness $\kappa$. 
The rate of increase in bearing capacity with level of preload in the over consolidated deposits changes at a threshold value of preload related to the maximum previous stress encountered by the soil. For OCR $=2$, the rate of increase in bearing capacity increased at a preload of $\sim 35 \%$ of the unconsolidated undrained capacity, after which the rate remained relatively constant. For an OCR $=4$, the threshold value of preload was higher, $\sim 50 \%$ of $\mathrm{v}_{\mathrm{u}}$, and for OCR $=10$, a threshold value was not observed for the maximum level of preload considered.

This threshold is linked to the load level at which the soil close to the foundation is loaded to beyond the previous pre-consolidation pressure, so that a given increase in load level leads to a more significant gain in strength. Below the threshold, the capacity rises at about $15 \%$ of the rate of applied preload, whereas above the threshold, a given increase in preload leads to a gain in capacity of $\sim 75 \%$ of this magnitude; the ratio of 5 between these values is close to the volumetric stiffness ratio, $\lambda / \kappa$.

\section{Simple prediction method for bearing capacity gain}

The gain in bearing capacity due to preloading and full primary consolidation for any level of preload and OCR can be predicted by analogy to the response of a single soil element following critical state theory (Schofield \& Wroth 1968). Elastic and plastic stress increments can be defined for an 'operative' preload pressure, defined as the applied preload, $\mathrm{v}_{\mathrm{p}}$ scaled by a constant 'stress factor', $\mathrm{f}_{\sigma}$, to account for the nonuniform distribution of stress in the zone of soil affected by the preload (and to account for the applied vertical stresses being considered, rather than the mean stresses). The operative shear strength, $\mathrm{s}_{\mathrm{u}, \mathrm{op}}$, can then be defined from the change in void ratio, $\Delta \mathrm{e}$, under the operative preload pressure, adjusted by a constant 'shear strength factor', $\mathrm{f}_{\mathrm{su}}$, 
to account for the non-uniform distribution of the increase in shear strength in the zone of soil that controls the consolidated bearing capacity.

Figure 7 illustrates the change in stress and state for an 'average' soil element i.e. a notional element representing the average response of the soil within the preloaded zone and the consolidated bearing capacity mechanism. From Figure 7 it can be deduced that if the pre-consolidation pressure and stress change are such that the stress state remains on an elastic recompression line (ERL), i.e. $\mathrm{f}_{\sigma} \mathrm{v}_{\mathrm{p}}<\sigma_{\mathrm{vc}}^{\prime}$, the change in void ratio is given by $\Delta \mathrm{e}=-\kappa \ln \left(\frac{\mathrm{f}_{\sigma_{\mathrm{p}}} \mathrm{v}_{\mathrm{p}}}{\sigma_{\mathrm{v} 0}^{\prime}}\right)$

If the stress state spans across an elastic recompression line and the normal compression line (NCL), i.e. $f_{\sigma} v_{p}>\sigma_{v c}^{\prime}$, the change in void ratio is given by

$$
\Delta \mathrm{e}=-\kappa \ln \left(\frac{\sigma_{\mathrm{vc}}^{\prime}}{\sigma_{\mathrm{v} 0}^{\prime}}\right)-\lambda \ln \left(\frac{\mathrm{f}_{\sigma} \mathrm{v}_{\mathrm{p}}}{\sigma_{\mathrm{vc}}^{\prime}}\right)
$$

Following critical state theory, a change in voids ratio due to preloading and consolidation leads to a proportional change in undrained shear strength according to

$$
\Delta \mathrm{e}=-\lambda \ln \left(\frac{\mathrm{s}_{\mathrm{u}, \text { con }}}{\mathrm{s}_{\mathrm{u}}}\right)
$$

The ratio of consolidated to in situ shear strength can then be expressed as 


$$
\frac{\mathrm{s}_{\mathrm{u}, \mathrm{con}}}{\mathrm{s}_{\mathrm{u}}}=\mathrm{f}_{\mathrm{su}} \exp \left(\frac{\Delta \mathrm{e}}{\lambda}\right)
$$

introducing $\mathrm{f}_{\mathrm{su}}$ as a scaling factor, as discussed above. It follows that the ratio of consolidated undrained bearing capacity to immediate, i.e. unconsolidated, undrained bearing capacity, $\mathrm{v}_{\mathrm{u}, \mathrm{cons}} / \mathrm{v}_{\mathrm{u}}$ is also given by Equation 5 .

Figure 8 shows predictions of the gain in bearing capacity using this approach (termed 'Method 1') compared with the finite element results. A stress factor, $\mathrm{f}_{\sigma}=0.8$ and an undrained shear strength factor, $\mathrm{f}_{\mathrm{s}}=0.45$ provided the best fit to the numerical results. The fit is reasonable - particularly the magnitude of absolute gain and the threshold at which the rate of gain increases - but the gain in bearing capacity for elastic stress changes is under predicted.

A better fit with the numerical data is achieved by adopting a different link between the preload stress and the corresponding increase in strength ('Method 2' in Figure 8). On the NCL, plastic stress leads to an increase in strength of $\mathrm{R} \Delta \sigma_{\mathrm{pl}}^{\prime}$, where $\mathrm{R}$ is the normally consolidated undrained strength ratio, $\mathrm{s}_{\mathrm{u}} / \sigma_{\mathrm{vc}}^{\prime}$. In the alternative approach, the elastic preload stress is scaled by the the ratio $\kappa / \lambda$ to approximate the increase in strength due to elastic recompression. This scales the change in voids ratio between elastic and plastic loading linearly with stress rather than logarithmically. The change in strength due to the preload is therefore given by

$$
\Delta \mathrm{s}_{\mathrm{u}}=\mathrm{f}_{\mathrm{su}} \mathrm{R}\left(\Delta \sigma_{\mathrm{pl}}^{\prime}+\frac{\kappa}{\lambda} \Delta \sigma_{\mathrm{el}}^{\prime}\right)
$$

where $\Delta \sigma_{\mathrm{pl}}^{\prime}$ and $\Delta \sigma_{\mathrm{el}}^{\prime}$ are the elastic and plastic stress components. 
For a pre-consolidation pressure and stress change for which the stress state remains on an elastic recompression line, i.e. $\mathrm{f}_{\sigma} \mathrm{v}_{\mathrm{p}}<\sigma_{\mathrm{vc}}^{\prime}$, the elastic stress is given by (Figure 7)

$\Delta \sigma^{\prime}{ }_{\mathrm{el}}=\mathrm{f}_{\sigma} \mathrm{v}_{\mathrm{p}}-\sigma_{\mathrm{v} 0}^{\prime}$

and the plastic stress, $\Delta \sigma_{\mathrm{pl}}^{\prime}=0$.

If the stress state spans across an elastic recompression line to the normal compression line, i.e. $f_{\sigma} v_{p}>\sigma_{v c}^{\prime}$, the elastic and plastic stresses are given by

$\Delta \sigma_{\mathrm{el}}^{\prime}=\sigma_{\mathrm{vc}}^{\prime}-\sigma_{\mathrm{v} 0}^{\prime}$ and $\Delta \sigma_{\mathrm{pl}}^{\prime}=\mathrm{f}_{\sigma} \mathrm{v}_{\mathrm{p}}-\sigma_{\mathrm{vc}}^{\prime}$

The gain in vertical bearing capacity can then be expressed in terms of the gain in operative undrained shear strength (from Equation 6)

$\frac{\mathrm{v}_{\mathrm{u}, \mathrm{con}}}{\mathrm{v}_{\mathrm{u}}}=1+\frac{\Delta \mathrm{s}_{\mathrm{u}}}{\mathrm{s}_{\mathrm{u}}}$

Comparing the theoretical predictions from 'Method 2' with the finite element results (Figure 8) indicates that a stress factor, $\mathrm{f}_{\sigma}=0.8$ and an undrained shear strength factor, $\mathrm{f}_{\mathrm{s}}=0.45$ provide the best fit (as in Method 1 ).

In both approaches, the stress factor affects the level of preload at which the rate of gain in capacity increases (i.e. it controls the position of the change in gradient of the curves in Figure 8) while the shear strength factor controls the rate of gain in capacity with preload (i.e. the gradient of the curves in Figure 8). 


\section{Time-settlement histories and selection of $c_{v}$}

Having established a simple way to assess the gain in bearing capacity for full consolidation under a given preload, an extension to account for partial consolidation is now introduced. Figure 9 shows the log time-settlement response of a strip and circular foundation on a normally consolidated deposit $(\mathrm{OCR}=1)$ for preloads at increments of $0.1 \mathrm{v}_{\mathrm{u}}$. Only the time dependent component of settlement is shown, i.e. the immediate settlement during load application is deducted from the total settlement. Time is represented by the dimensionless time factor

$\mathrm{T}=\frac{\mathrm{C}_{\mathrm{v}} \mathrm{t}}{\mathrm{B}^{2}}, \frac{\mathrm{C}_{\mathrm{v}} \mathrm{t}}{\mathrm{D}^{2}}$

where $c_{v}$ is a representative value of the coefficient of consolidation, $t$ is the elapsed time since the start of consolidation and B or D is the breadth or diameter of a strip or circular foundation. The coefficient of consolidation is taken as

$\mathrm{c}_{\mathrm{v}}=\frac{\mathrm{k}}{\mathrm{m}_{\mathrm{v}} \gamma_{\mathrm{w}}}$

where $\mathrm{k}$ is the soil permeability, $\gamma_{\mathrm{w}}$ is the unit weight of water $\left(9.81 \mathrm{kN} / \mathrm{m}^{3}\right)$ and $\mathrm{m}_{\mathrm{v}}$ is the modulus of compressibility given by

$\mathrm{m}_{\mathrm{v}}=\frac{\lambda}{(1+\mathrm{e}) \sigma_{\mathrm{v} 0}^{\prime}}$

where $\lambda$ is the virgin compression index, e is a representative value of void ratio, (with specific volume given by $\mathrm{v}=1+\mathrm{e}$ ) and $\sigma_{\mathrm{v} 0}^{\prime}$ is the relevant vertical effective stress. The 'in situ' coefficient of consolidation, $\mathrm{c}_{\mathrm{v} 0}$, is defined based on the in situ void ratio, $\mathrm{e}_{0}$, 
and vertical stress level, $\sigma_{\mathrm{v} 0}^{\prime}$, taken at mudline level prior to preloading, and is used in the calculation of the time factor presented in Figure 9.

Comparison of results for the rough and smooth foundation-soil interface showed the time-settlement response to be independent of interface roughness, so the results presented are equally applicable to smooth or rough-based foundations.

Smaller settlements and faster consolidation were observed for the circular foundation compared with the strip foundation in equivalent conditions. The same comparative rate has been reported for elastic soil (Davis and Poulos 1972), and is to be expected as a result of three-dimensional flow rather than more restrictive plane strain flow. Settlement of the circular foundation was around half that of the strip foundation under the same relative preload, and full consolidation occurred an order of magnitude quicker.

The degree of consolidation, defined by the normalised settlement response, $U=\mathrm{w} / \mathrm{w}_{\mathrm{f}}$, is shown for each OCR for the strip and circular foundations (smooth or rough-based) as a function of dimensionless time factor $\mathrm{T}$ in Figure 10. The in situ coefficient of consolidation, $\mathrm{C}_{\mathrm{v} 0}$, is used in the calculation of the time factor presented in Figure 10. The broken lines indicate the limits of the spread of data, showing that $\mathrm{T}_{50}$ varies over two orders of magnitude (from 0.008 to 0.2 ). Variations in the normalised timesettlement response result from differences in foundation geometry, level of preload and OCR, but are independent of foundation interface roughness. All other things being equal, the time-settlement histories of the circular foundations lie to the left of the strip case, and those for higher OCR plot increasingly to the left. The level of preload has the least significant effect on the normalised time-settlement histories. 
Figure 11 shows the normalised time-settlement response based on an 'operative', rather than initial, coefficient of consolidation, $\mathrm{C}_{\mathrm{v}}$. The operative coefficient of consolidation accounts for the changing stress state in the soil for each preload level and OCR, and whether the consolidated stress state lies on the normal compression line or an elastic recompression line. The operative coefficient of consolidation is derived as a weighted proportion of a maximum value of the coefficient of consolidation, $\mathrm{C}_{\mathrm{v}, \text { max }}$, estimated using a stiffness, $m_{v}$, linked to a factored stress range $\left(f_{\sigma} v_{p}-\sigma_{v 0}^{\prime}\right)$ and the in situ coefficient of consolidation, $c_{v 0}$. In other words, $c_{v}$ is given by Equation 11 with the relevant coefficient of compressibility calculated by

$$
\mathrm{m}_{\mathrm{v}}=\frac{\Delta \mathrm{e} /(1+\mathrm{e})}{\mathrm{f}_{\sigma} \mathrm{v}_{\mathrm{p}}-\sigma_{\mathrm{v} 0}^{\prime}}
$$

Where $\Delta \mathrm{e}$ is calculated from Equations 2 and 3, e is taken as the in situ value of void ratio at the mudline, $\mathrm{e}_{0}$, and $\Delta \mathrm{p}^{\prime}$ is given by the factored stress range $\mathrm{f}_{\sigma} \mathrm{v}_{\mathrm{p}}-\sigma_{\mathrm{v} 0}^{\prime}$.

Results from the finite element analysis indicate that a weighting of the initial value of the coefficient of consolidation to the maximum value in the ratio of 0.8:0.2 provides close banding of the normalised time-settlement histories for each level of preload and OCR, i.e.

$$
\mathrm{c}_{\mathrm{v}}=0.8 \mathrm{c}_{\mathrm{v} 0}+0.2 \mathrm{c}_{\mathrm{v}, \max }
$$

The time-settlement histories of the circular foundations lie to the left of those for the strip foundations due to the more rapid consolidation resulting from radial drainage. $T_{50}$ varies by a factor of $\sim 2.5$ across each band, compared with the two orders of magnitude spread when the data is normalised by the in situ coefficient of consolidation $c_{v 0}$ (as 
shown in Figure 10), and indicated by the broken lines in Figure 11. This confirms that the operative $c_{v}$ approach provides an effective normalisation of all responses.

The normalised time-settlement response of the strip and circular foundations can be approximated by a simple function.

$$
\mathrm{U}=\frac{\mathrm{w}}{\mathrm{w}_{\mathrm{f}}}=\frac{1}{1+\left(\mathrm{T} / \mathrm{T}_{50}\right)^{\mathrm{m}}}
$$

where $\mathrm{T}_{50}$ is the dimensionless time factor for $50 \%$ of the consolidation settlement to occur (i.e. $\mathrm{U}=\mathrm{w} / \mathrm{w}_{\mathrm{f}}=0.5$ ) and $\mathrm{m}$ is a constant. Values of $\mathrm{T}_{50}$ and the constant $\mathrm{m}$ that best fit the bands of finite element results for the strip and circular foundation geometry when the time factor is calculated in terms of the operative coefficient of consolidation, are summarised in Table 2.

\section{Consolidated undrained bearing capacity following partial consolidation}

Figure 12 shows the effect of the duration of the consolidation period on the normalised load-displacement response to failure for a rough-based strip foundation under a preload of $0.3 \mathrm{v}_{\mathrm{u}}$ on a normally consolidated deposit $(\mathrm{OCR}=1)$. Greater gains in the early stages of consolidation are evident, as would be expected. A similar trend of gain in undrained capacity was observed for each OCR considered, although for OCR $=10$, the maximum relative gain is five-fold less and the absolute time scale is an order of magnitude less than in the normally consolidated case.

Figure 13 shows the increase in bearing capacity as a continuous function of time, expressed as dimensionless time factor, for discrete intervals of preload. This representation reiterates that the great majority of the gain in bearing capacity - and by 
inference, the great majority of the increase in shear strength - is achieved in the early part of the period of consolidation.

Figure 14 shows the gain in undrained bearing capacity for each of the preload levels, consolidation periods, OCR and foundation geometries considered in this study compared with the foundation settlement normalized by the breadth or diameter. The data are reasonably tightly banded for strip and circular foundation geometry and a lower limit can be described by a linear relationship, shown on Figure 14 by the broken lines. The higher gradient for the circular foundation indicates that a greater gain in bearing capacity is achieved with smaller relative foundation settlements compared with a strip foundation, although smaller final settlements are experienced for the circular case.

A 'hardening rule' approach for linking consolidated undrained bearing capacity to accumulated settlement, as shown in Figure 14, was suggested by Bransby (2002). Extending this notion, Figure 15a shows the data from Figure 14 normalized with respect to the ultimate gain in capacity and settlement, i.e. the proportion of the maximum gain in bearing capacity $\left(\mathrm{G}=\mathrm{v}_{\mathrm{u}, \text { cons }} / \mathrm{V}_{\mathrm{u}, \text { cons_max }}\right) \mathrm{vs}$. the degree of consolidation $\left(\mathrm{U}=\mathrm{w} / \mathrm{w}_{\mathrm{f}}\right)$. The outliers are cases of small absolute gain in bearing capacity associated with small preloads for all OCRs or all preloads for high OCR. The linear fit is always conservative. Only cases of absolute gains of less than $10 \%$, which are of little practical relevance, do not fit this line. Figure 15b shows the same representation as Figure 15a omitting data series for cases of absolute gains of less than $10 \%$. The resulting 1:1 relationship between normalized gain and degree of consolidation can be used to predict 
the consolidated undrained bearing capacity for a given preload, OCR and degree of consolidation:

$\mathrm{v}_{\mathrm{u}, \text { cons }}=\mathrm{U} \cdot \mathrm{v}_{\mathrm{u}, \text { cons__max }}$

An example of applying the methodology proposed here is outlined in the following section.

\section{SUMMARY OF PREDICTION METHODOLOGY}

In summary, the consolidated undrained vertical bearing capacity of a surface foundation resting on a deposit with known OCR and critical state parameters $\left(\lambda, \kappa, e_{0}\right)$, subjected to a given magnitude and duration of preload, can be predicted with the following methodology.

1. Calculate the immediate, i.e. unconsolidated, undrained vertical bearing capacity, $\mathrm{v}_{\mathrm{u}}$, for a given foundation geometry and in situ shear strength profile, $\mathrm{v}_{\mathrm{u}}=\mathrm{N}_{\mathrm{c}} \mathrm{As} \mathrm{s}_{\mathrm{u}}$.

2. Calculate the relative preload $\mathrm{v}_{\mathrm{p}} / \mathrm{v}_{\mathrm{u}}$.

3. Calculate the maximum gain in vertical bearing capacity i.e. associated with full consolidation (Eqn 9).

4. Calculate the operative coefficient of consolidation $C_{v}$ (Eqns 11 \& 13), i.e. based on the OCR and preload $\mathrm{v}_{\mathrm{p}} / \mathrm{v}_{\mathrm{u}}$.

5. Calculate the time factor $\mathrm{T}$ associated with the design period of consolidation based on the operative coefficient of consolidation (Eqn 10). 
6. Calculate the degree of consolidation $U$ for the time factor $T$ associated with the design period of consolidation (Eqn 16 \& Table 2).

7. Calculate the consolidated undrained bearing capacity from the predicted maximum gain (from step 3) and the degree of consolidation (from step 6) (Eqn 17).

This approach, linking consolidation responses at soil element and foundation scale, is in the same class as the methods for predicting undrained foundation settlement set out in Atkinson (2000) and Osman \& Bolton (2005). The detailed spatial variation in soil deformation around the foundation is accommodated by simple scaling factors, which are shown by more sophisticated simulations to be adequate for engineering purposes.

The method in this paper, as outlined above, is general, and could also be applied to the prediction of increases in capacity under horizontal loads, moments or torsion. The stress and shear strength factors used to predict maximum gain are a function of the loading direction, or more strictly of the extent of the zones of preload and subsequent shearing at failure. For example, the stress and strength factors for capacity of a surface foundation under horizontal load or torsion would be higher since the region of shearing in pure horizontal or torsional failure mechanisms will coincide with the zone of maximum strength increase (in contrast to the case of vertical or moment capacity where the shear strength varies over the region of the more extensive failure mechanisms) - as identified for horizontal loading by Bransby (2002). Future studies could extend the approach provided in this paper by deriving stress and shear strength factors for alternative load paths or moments. 
The method is equally applicable to embedded shallow foundations, although the type of embedment (i.e. buried plate, solid, skirted) and the interface roughness along the embedded portion of the foundation will affect the proportion of applied preload transferred to the soil at foundation level so the particular boundary conditions should be explicitly considered (Gourvenec \& Randolph 2009, 2010).

\section{CONCLUDING REMARKS}

This paper has presented results of finite element analyses investigating the effect of preloading and consolidation on the undrained bearing capacity of surface strip and circular foundations on soft and stiff clay. For the conditions considered in this study, the results of the analyses showed:

- Interface roughness did not affect the consolidation response or the relative gain in undrained vertical bearing capacity for surface strip or circular foundations.

- Shape effects slightly reduced the relative gain in undrained vertical bearing capacity in a normally consolidated deposit but had negligible effect for OCR $>1$.

- Three-dimensional flow and strain led to a higher rate of consolidation around a circular foundation compared to plane strain conditions, all other things being equal.

- Three-dimensional flow and strain led to greater relative gain in vertical bearing capacity for given foundation settlement compared with plane strain conditions, but lower ultimate foundation settlement and relative gain in bearing capacity. 
- Increasing over consolidation ratio increased the rate of consolidation but reduced the potential gain in bearing capacity (due to the reduced potential for significant reduction in void ratio under practical preloads).

- Significant gain in bearing capacity can be achieved in practical time frames, particularly in a normally consolidated deposit.

A methodology has been proposed for predicting potential gain in bearing capacity as a function of the relative preload and degree of consolidation through a simple hardening rule.

The results and methodology presented in this paper provide a framework for predicting the undrained consolidated bearing capacity of smooth or rough strip and circular foundations resting on a single layer material with linearly increasing shear strength with depth and a range of OCR. The methodology is applicable to other boundary conditions (e.g. foundation geometry, embedment, load paths, layered materials) but the specific factors and fits require optimisation for specific design conditions.

\section{LIST OF NOTATION}

$\begin{array}{ll}\text { B } & \text { Foundation breadth } \\ \mathrm{C}_{\mathrm{v}} & \text { Coefficient of consolidation } \\ \mathrm{C}_{\mathrm{v} 0} & \text { In situ coefficient of consolidation } \\ \mathrm{C}_{\mathrm{v}, \max } & \text { Maximum coefficient of consolidation over stress range } \\ \mathrm{D} & \text { Foundation diameter } \\ \text { e } & \text { Void ratio }\end{array}$




\begin{tabular}{|c|c|}
\hline $\mathrm{e}_{0}$ & In situ void ratio \\
\hline $\mathrm{f}_{\mathrm{su}}$ & Strength factor \\
\hline $\mathrm{f}_{\sigma}$ & Stress factor \\
\hline G & Proportional maximum gain in bearing capacity ( $\left.=\mathrm{v}_{\mathrm{u}, \text { cons }} / \mathrm{v}_{\mathrm{u}, \text { cons_max }}\right)$ \\
\hline $\mathrm{k}$ & Permeability \\
\hline $\mathrm{K}_{0}^{\mathrm{nc}}$ & In situ earth pressure coefficient of normally consolidated deposit \\
\hline $\mathrm{K}_{0}^{\mathrm{oc}}$ & In situ earth pressure coefficient of over consolidated deposit \\
\hline $\mathrm{m}$ & Constant defining a power in fitting expression \\
\hline $\mathrm{m}_{\mathrm{v}}$ & Modulus of compressibility \\
\hline M & Stress ratio at the critical state \\
\hline $\mathrm{N}_{\mathrm{c}}$ & Dimensionless vertical bearing capacity factor \\
\hline $\mathrm{p}^{\prime}$ & Mean normal effective stress \\
\hline q & Deviatoric stress \\
\hline $\mathrm{R}$ & Normally consolidated undrained strength ratio, $\mathrm{s}_{\mathrm{u}} / \sigma_{\mathrm{vc}}^{\prime}$ \\
\hline $\mathrm{S}_{\mathrm{u}}$ & Plane strain undrained shear strength \\
\hline $\mathrm{Su} 0$ & In situ undrained shear strength \\
\hline $\mathrm{S}_{\mathrm{u}, \mathrm{cons}}$ & Consolidated undrained shear strength \\
\hline $\mathrm{S}_{\mathrm{u}, \mathrm{op}}$ & Operative undrained shear strength \\
\hline $\mathrm{t}$ & Time \\
\hline $\mathrm{T}$ & Dimensionless time factor \\
\hline $\mathrm{T}_{50}$ & Time for $50 \%$ consolidation to occur \\
\hline $\mathrm{V}_{\mathrm{u}}$ & Unconsolidated undrained uniaxial vertical bearing capacity per unit area \\
\hline $\mathrm{v}_{\mathrm{p}}$ & Preload stress \\
\hline $\mathrm{V}_{\mathrm{u}, \text { cons }}$ & Consolidated undrained uniaxial vertical bearing capacity per unit area \\
\hline $\mathrm{V}_{\mathrm{u}, \text { cons_max }}$ & Maximum consolidated undrained uniaxial vertical bearing capacity per unit area \\
\hline $\mathrm{w}$ & Vertical displacement of foundation \\
\hline $\mathrm{W}_{\mathrm{f}}$ & Final vertical displacement of foundation \\
\hline$\Delta \sigma_{\mathrm{el}}^{\prime}$ & Elastic stress component \\
\hline$\Delta \sigma_{\mathrm{pl}}^{\prime}$ & Plastic stress component \\
\hline
\end{tabular}




$\begin{array}{ll}\phi & \text { Internal angle of friction of soil } \\ \gamma & \text { Unit self-weight of soil } \\ \gamma_{\mathrm{w}} & \text { Unit self-weight of water } \\ \kappa & \text { Recompression index } \\ \lambda & \text { Virgin compression index } \\ \theta & \text { Lode's angle } \\ \sigma_{\mathrm{v} 0}^{\prime} & \text { In situ vertical effective stress } \\ \sigma_{\mathrm{vc}}^{\prime} & \text { Consolidated vertical effective stress }\end{array}$

\section{ACKNOWLEGEMENTS}

This work forms part of the activities of the Centre for Offshore Foundation Systems (COFS), currently supported as a node of the Australian Research Council Centre of Excellence for Geotechnical Science and Engineering. The work presented in this paper was supported through ARC grant DP0988904. This support is gratefully acknowledged. 


\section{REFERENCES}

Atkinson, J. H. (2000) Non-linear soil stiffness in routine design. Géotechnique,50(5): $487-507$.

Booker, J.R. and Small, J.C (1986). The behaviour of an impermeable flexible raft on a deep layer of consolidating soil. International Journal for Numerical and Analytical Methods in Geomechanics, 10: 311 - 327.

Bransby, M.F. (2002). The undrained inclined load capacity of shallow foundations after consolidation under vertical loads. Proc. $8^{\text {th }}$ Numerical Models in Geomechanics (NUMOG), Rome, 431-437.

Butterfield, R. and Banerjee, P.K. (1971). A rigid disc embedded in an elastic half space. Geotechnical Engineering, 2(1): 35-52.

Davis, E.H. and Poulos, H.G. (1972). Rate of settlement under two- and threedimensional conditions. Géotechnique, 22(1): 95 - 114.

Gourvenec, S. and Randolph, M.F. (2009). Effect of foundation embedment and soil properties on consolidation response, Proc. Int. Conf. Soil Mechanics and Geotechnical Engineering (ICSMGE), Alexandria, Egypt. 638-641.

Gourvenec, S. and Randolph, M.F. (2010) Consolidation beneath skirted foundations due to sustained loading. International Journal of Geomechanics, 10(1): 22 - 29. 
Lehane, B.M. and Gaudin, C. (2005). Effects of drained pre-loading on the performance of shallow foundations on over consolidated clay. Proc. Offshore Mechanics and Arctic Engineering (OMAE), OMAE2005-67559.

Lehane, B.M. and Jardine, R.J. (2003). Effects of long-term preloading on the performance of a footing on clay. Géotechnique, 53(8): 689 - 695.

Martin, C.M. (2003). New software for rigorous bearing capacity calculations. Proc. British Geotech. Assoc. Int. Conf. on Foundations, Dundee, 581-592.

Osman, A.S. and Bolton, M.D. (2005) Simple plasticity-based prediction of the undrained settlement of shallow circular foundations on clay. Géotechnique, 55(6): 435 - 447.

Schofield, A.N. and Wroth, C.P. (1968) Critical state soil mechanics. McGraw-Hill, London.

Zdravkovic, L. Potts, D.M. and Jackson, C. (2003). Numerical study of the effect of preloading on undrained bearing capacity. Int. J. Geomechanics ASCE, September, 1 - 10 . 
Table 1. Soil properties used in finite element analyses

\begin{tabular}{|l|l|}
\hline Parameter input for FEA & Magnitude \\
\hline $\begin{array}{l}\text { Index and engineering parameters } \\
\text { Unit weight }\left(\gamma, \mathrm{kN} / \mathrm{m}^{3}\right)\end{array}$ & 17.18 \\
$\quad$ Permeability $(\mathrm{k}, \mathrm{m} / \mathrm{s})$ & $1.3 \mathrm{E}-10$ \\
Elastic parameters (as a porous elastic material) & \\
$\quad \begin{array}{l}\text { Recompression index }(\kappa) \\
\text { Poisson's ratio }\left(\mathrm{v}^{\prime}\right)\end{array}$ & 0.044 \\
Tensile limit & 0.25 \\
Clay plasticity parameters & \\
$\quad$ Virgin compression index $(\lambda)$ & 0.205 \\
$\quad$ Stress ratio at critical state $\left(\mathrm{M}=\mathrm{q} / \mathrm{p}^{\prime}\right)$ & 0.898 \\
$\quad$ Wet yield surface size $(\beta)^{1}$ & 1 \\
$\quad$ Flow stress ratio & 1 \\
Intercept $\left(\mathrm{e}_{1}\right.$, at $\mathrm{p}^{\prime}=1$ on $\left.\mathrm{NCL}\right)$ & 2.14 \\
\hline
\end{tabular}

Table 2. Values of $\mathbf{T}_{50}$ and constant ' $m$ ' for fits to normalised time-settlement response (Equation 16)

\begin{tabular}{|l|c|c|}
\hline & $\mathbf{T}_{\mathbf{5 0}}$ & $\mathbf{m}$ \\
\hline Strip foundation & 0.17 & 0.95 \\
\hline Circular foundation & 0.035 & 1.05 \\
\hline
\end{tabular}




\section{FIGURES}

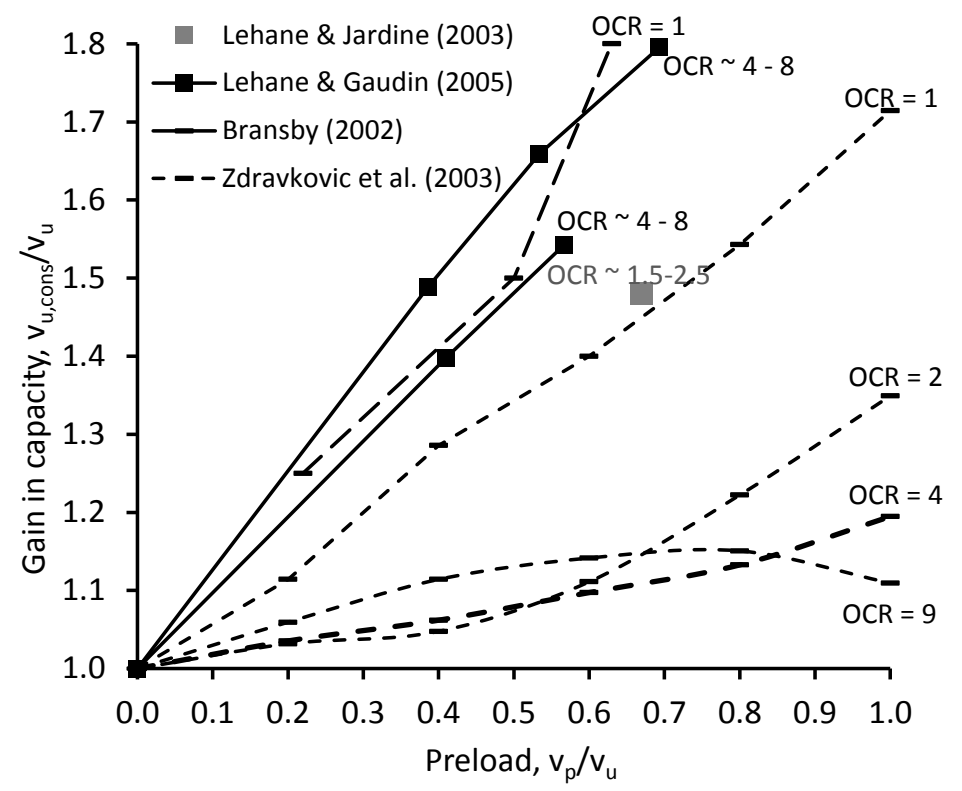

Figure 1. Comparison of published data on consolidated undrained vertical bearing capacity of shallow foundations

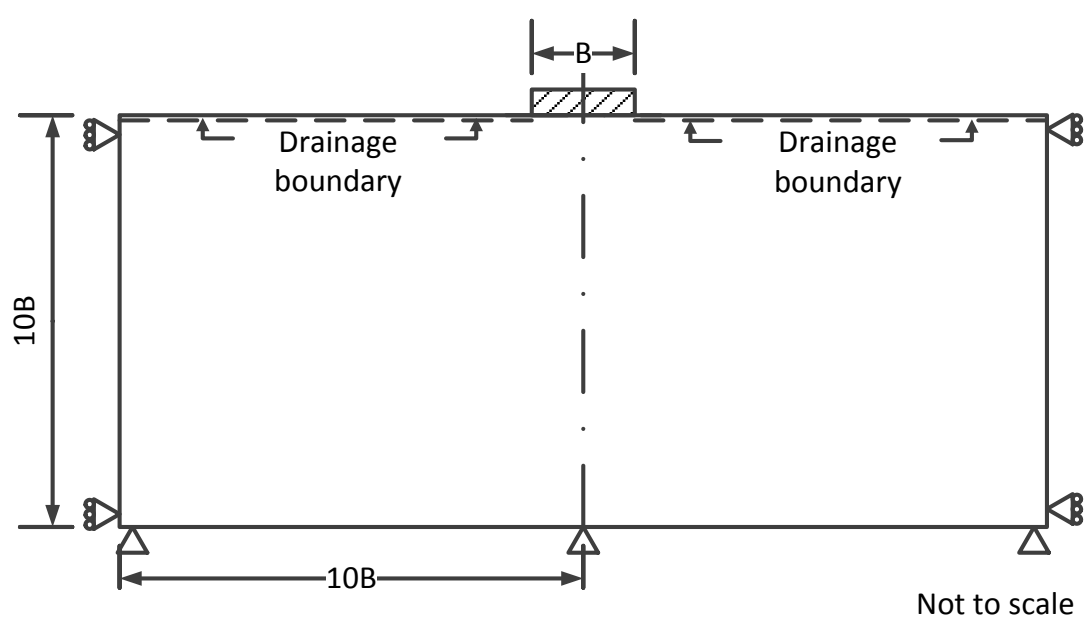

Figure 2. Schematic representation of the boundary value problem 


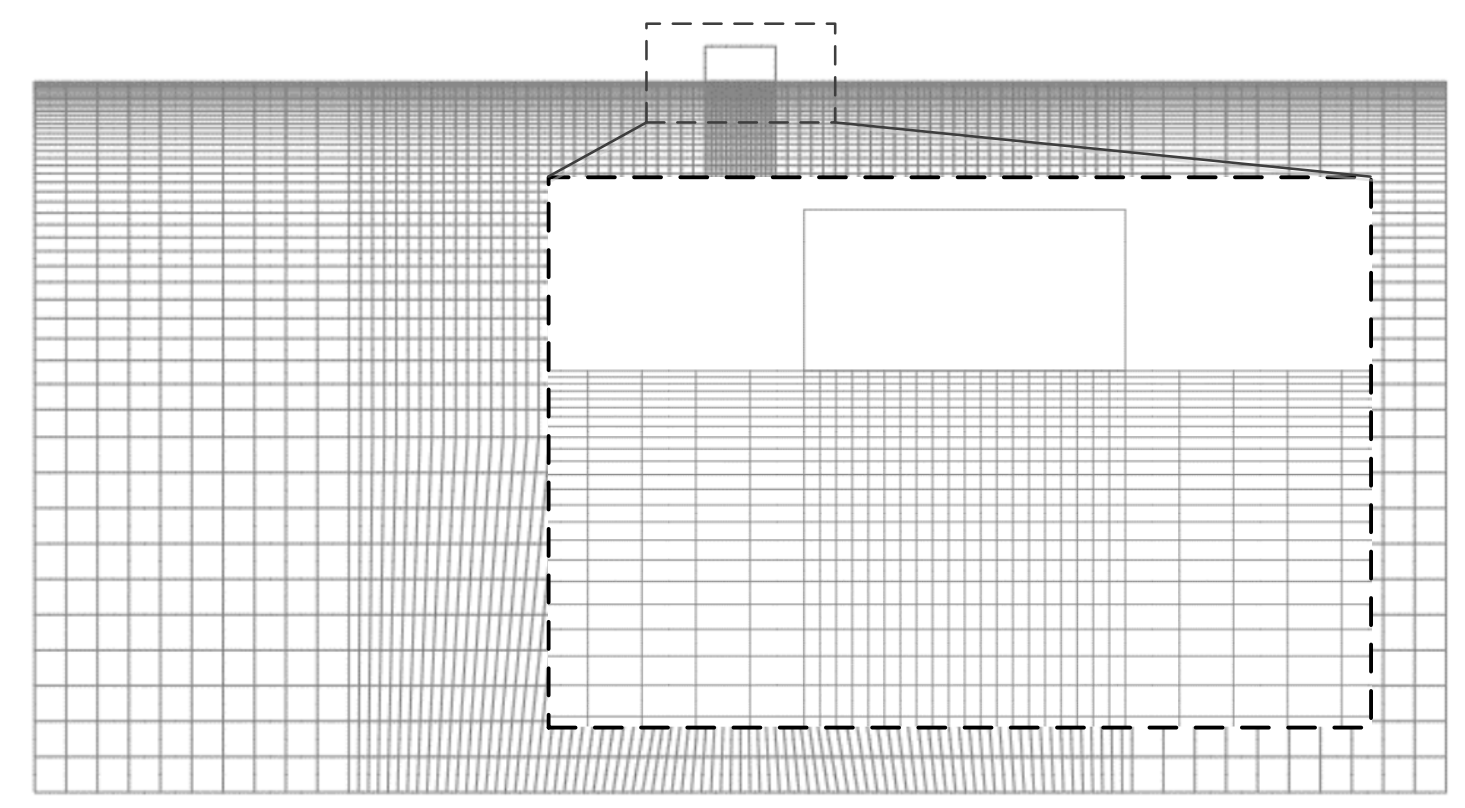

Figure 3. Example of finite element mesh for plane strain analysis

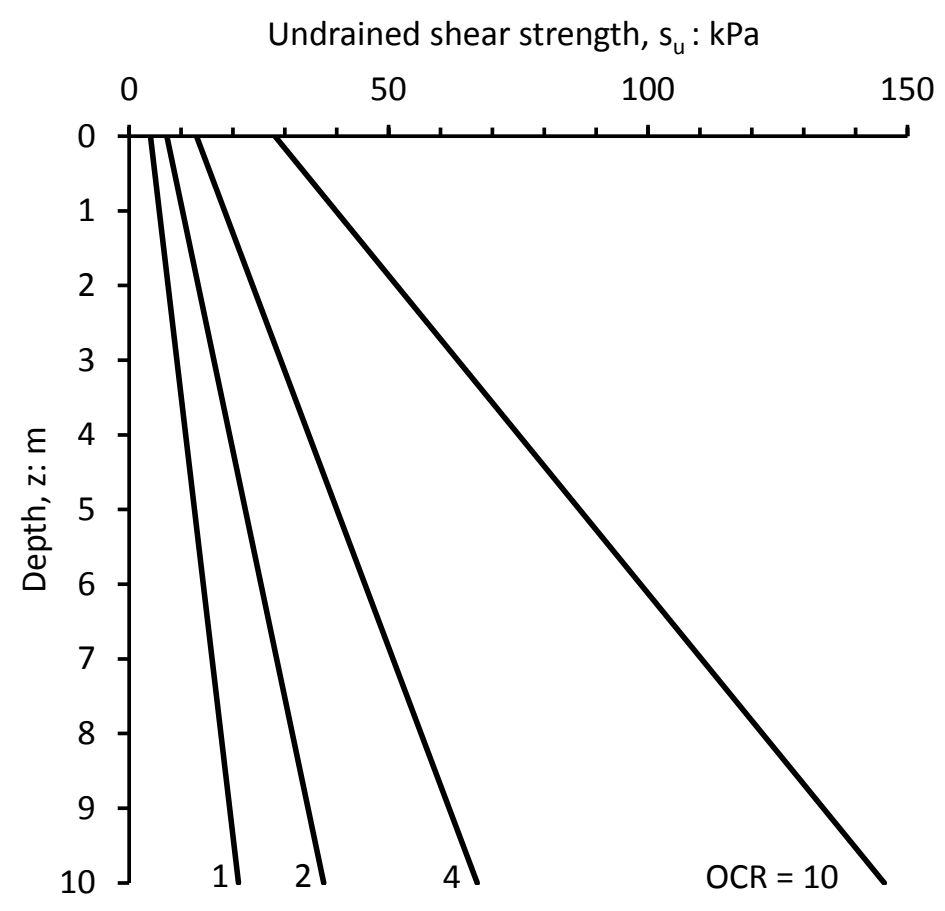

Figure 4. Undrained shear strength profiles of modelled conditions 


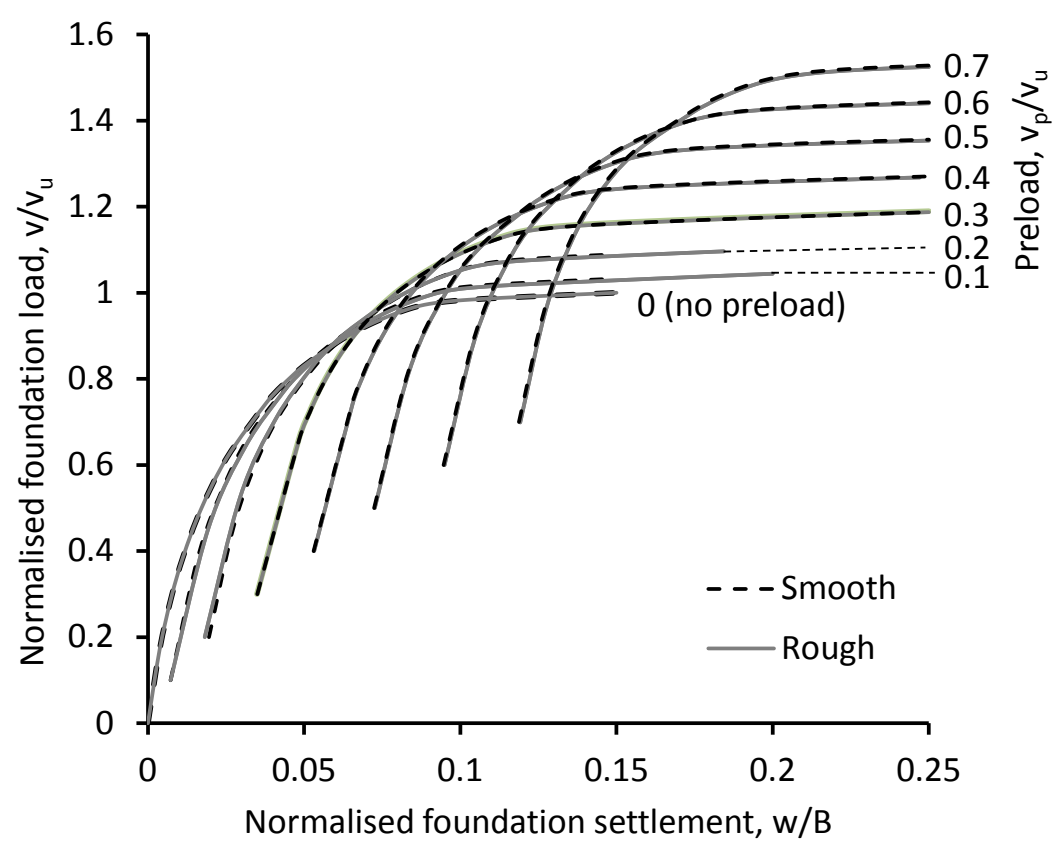

Figure 5. Normalised load-settlement response to failure following preloading and full primary consolidation of strip foundations

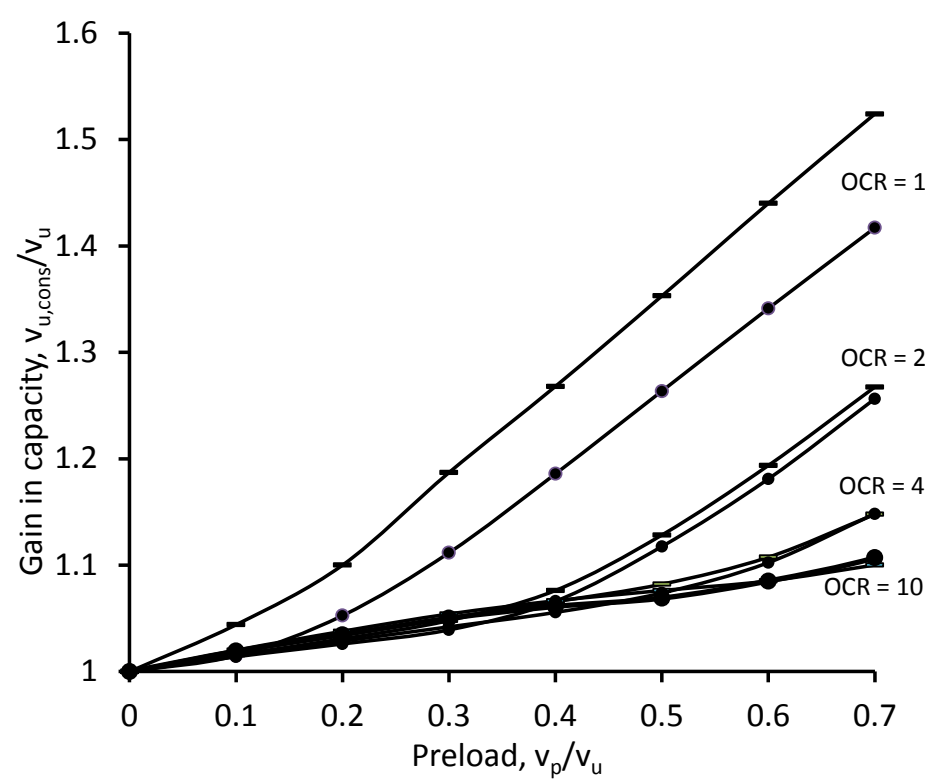


Figure 6. Observed gain in undrained bearing capacity due to preloading and full primary consolidation

In situ stress at

foundation

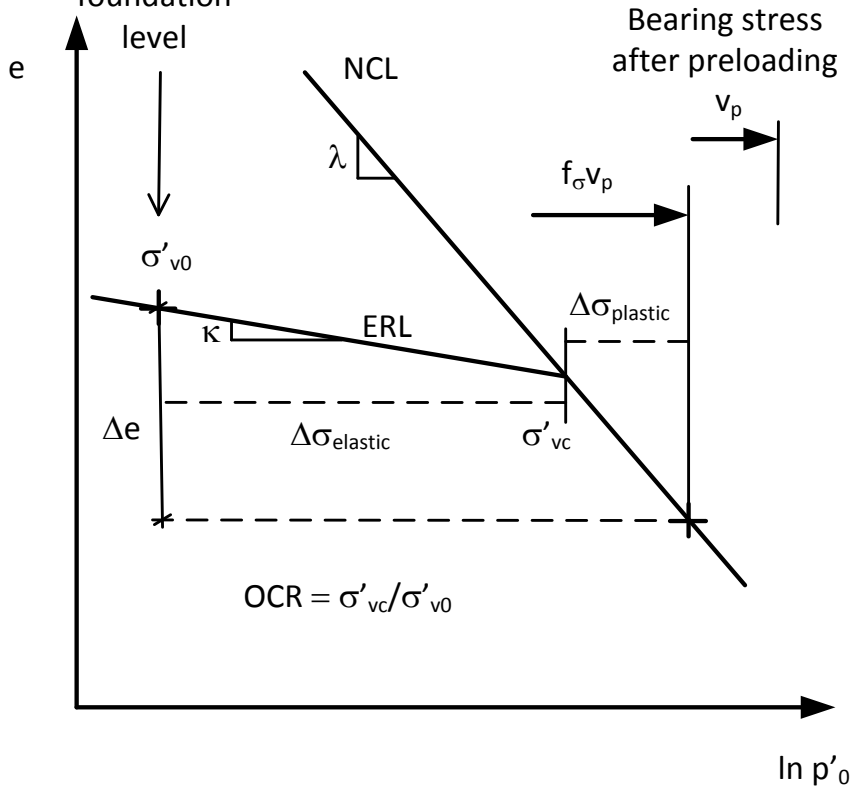

Figure 7. Representation of soil stress and state and definition of nomenclature 

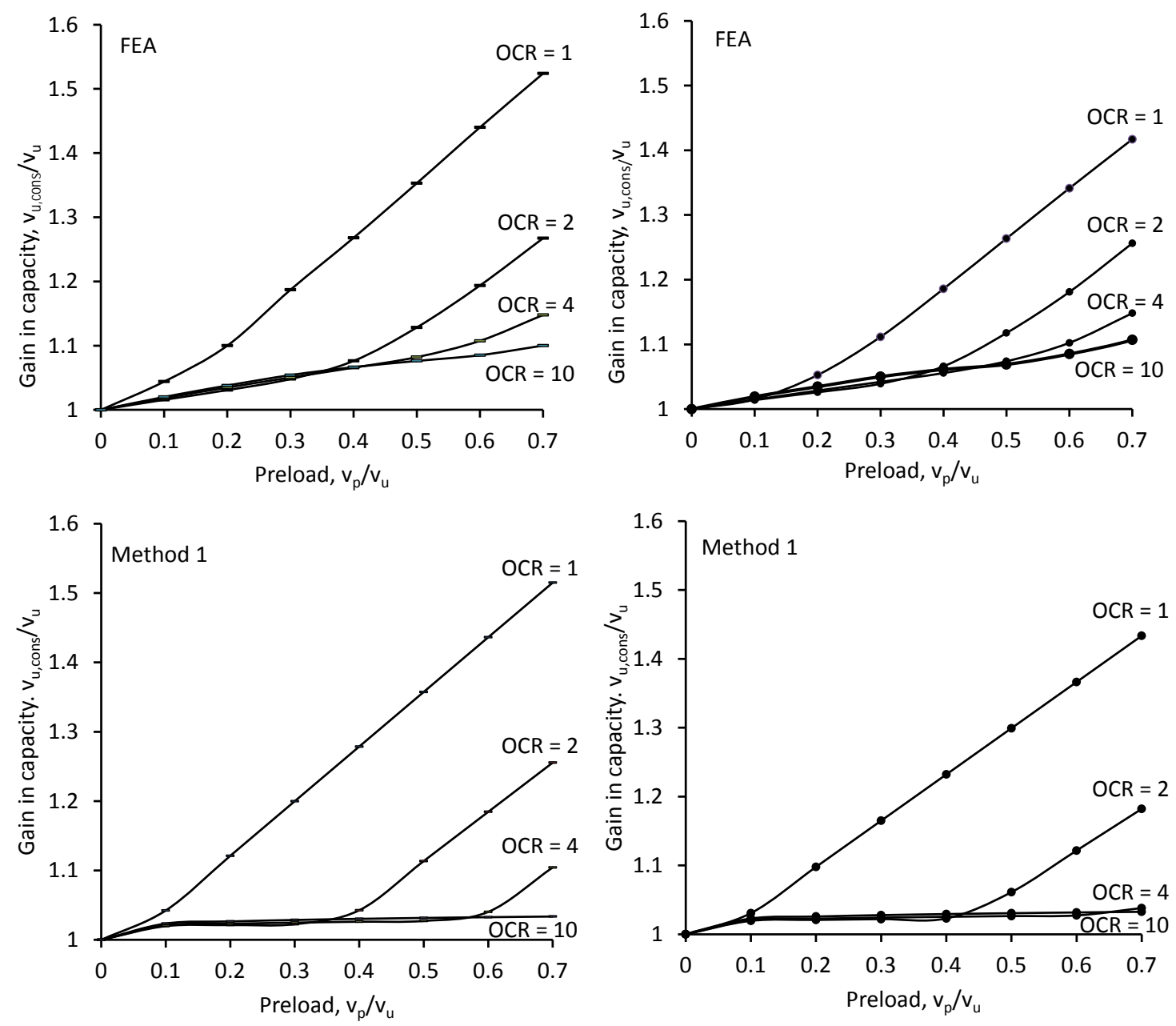

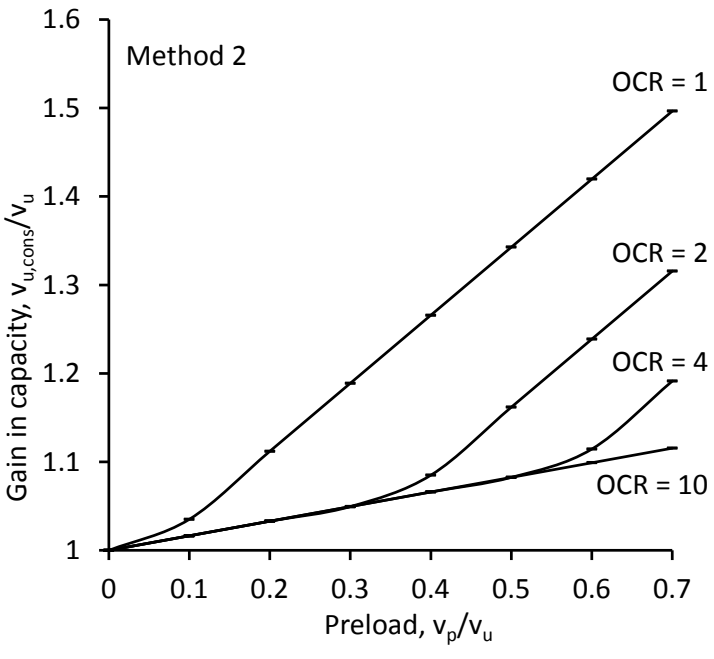

(a) Strip foundations

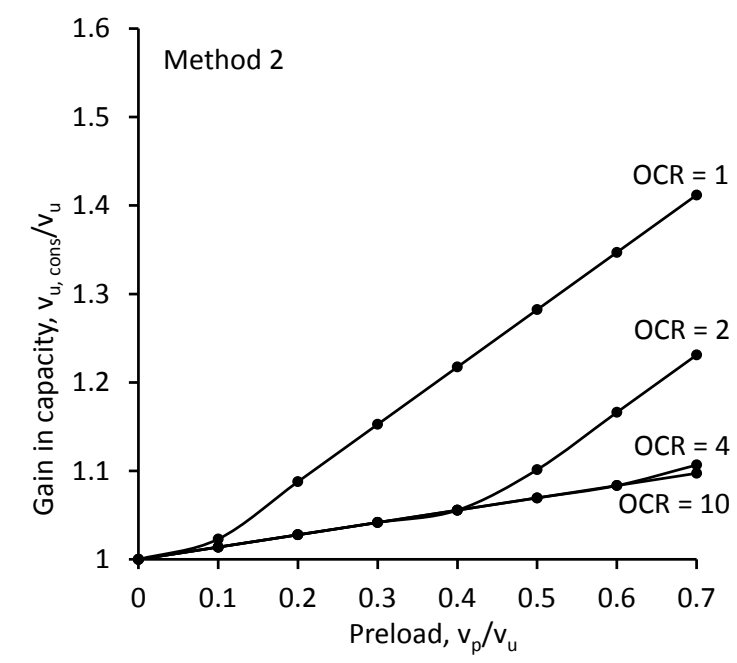

(b) Circular foundations

Figure 8. Predicted and observed gain in undrained bearing capacity due to preloading and full primary consolidation 


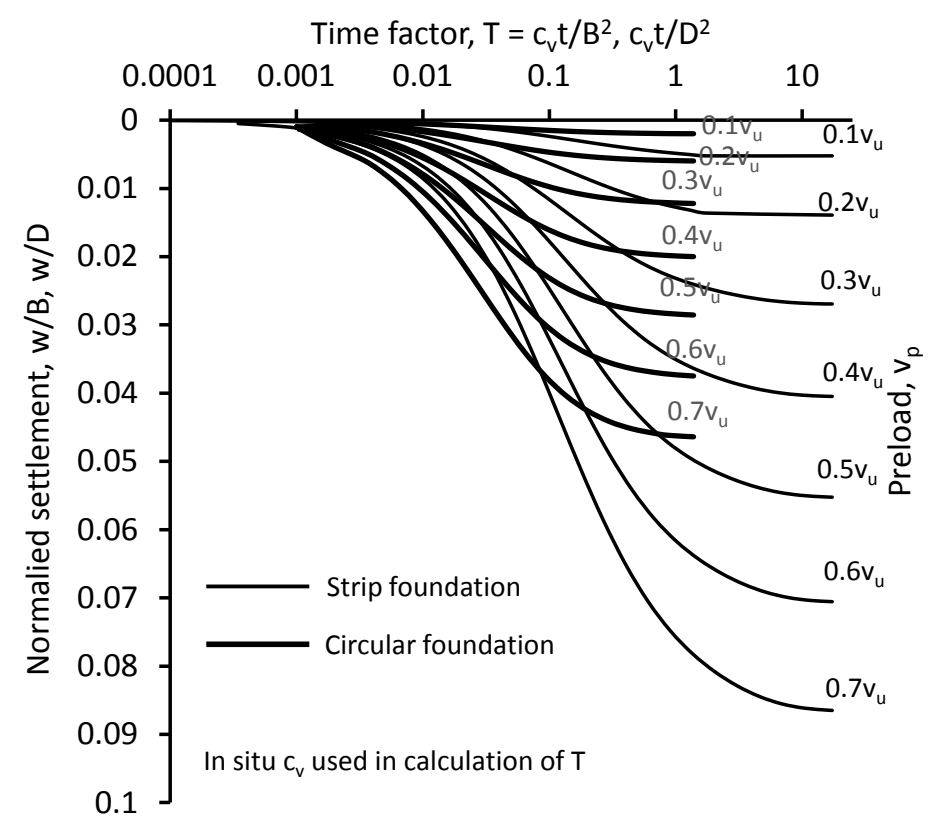

Figure 9. Normalised time-settlement response of smooth or rough-based strip and circular foundations on a normally consolidated deposit $(O C R=1)$; in situ $\mathrm{C}_{v}$ used in calculation of $T$

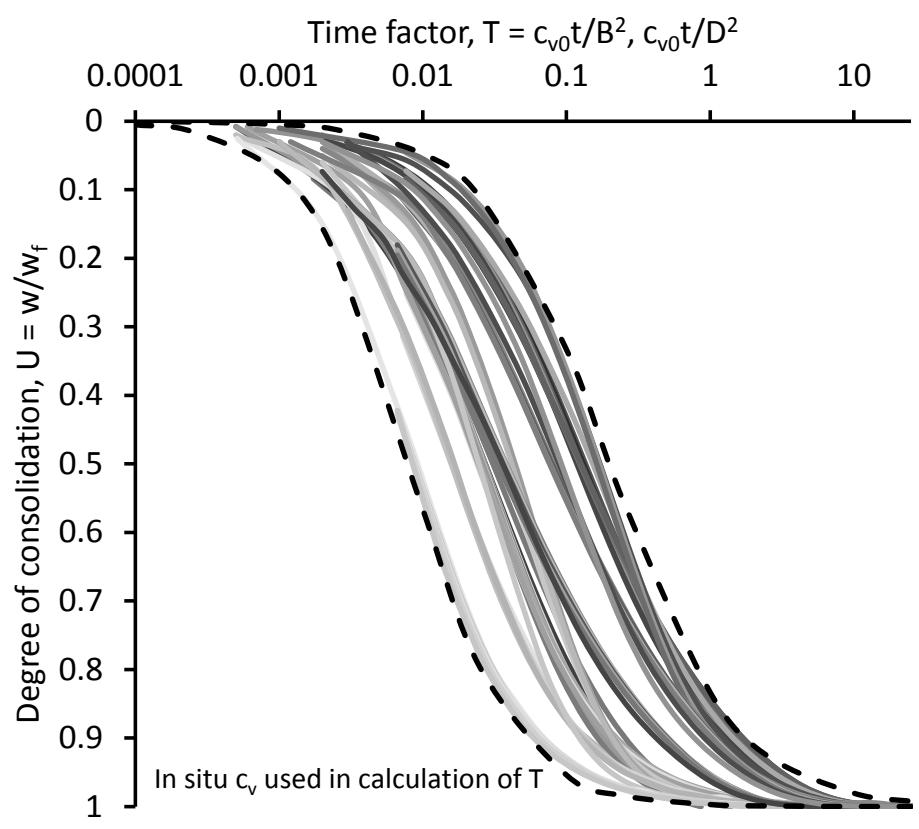

Figure 10. Normalised time-settlement response of smooth or rough-based strip and circular foundations on deposits with varying OCR under a range of preload; in situ $\mathrm{C}_{\mathrm{v}}$ used in calculation of $T$ 


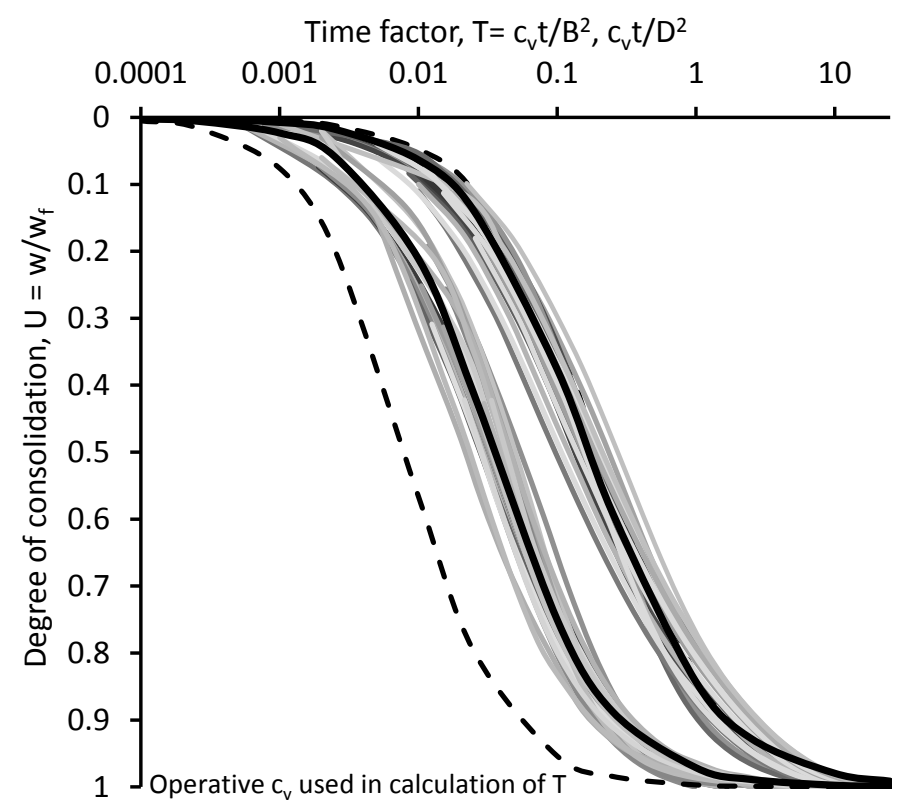

Figure 11. Normalised time-settlement response of smooth or rough-based strip and circular foundations on deposits with varying OCR under a range of preload and mean curve fits; operative $\mathrm{C}_{\mathrm{v}}$ used in calculation of $\mathrm{T}$

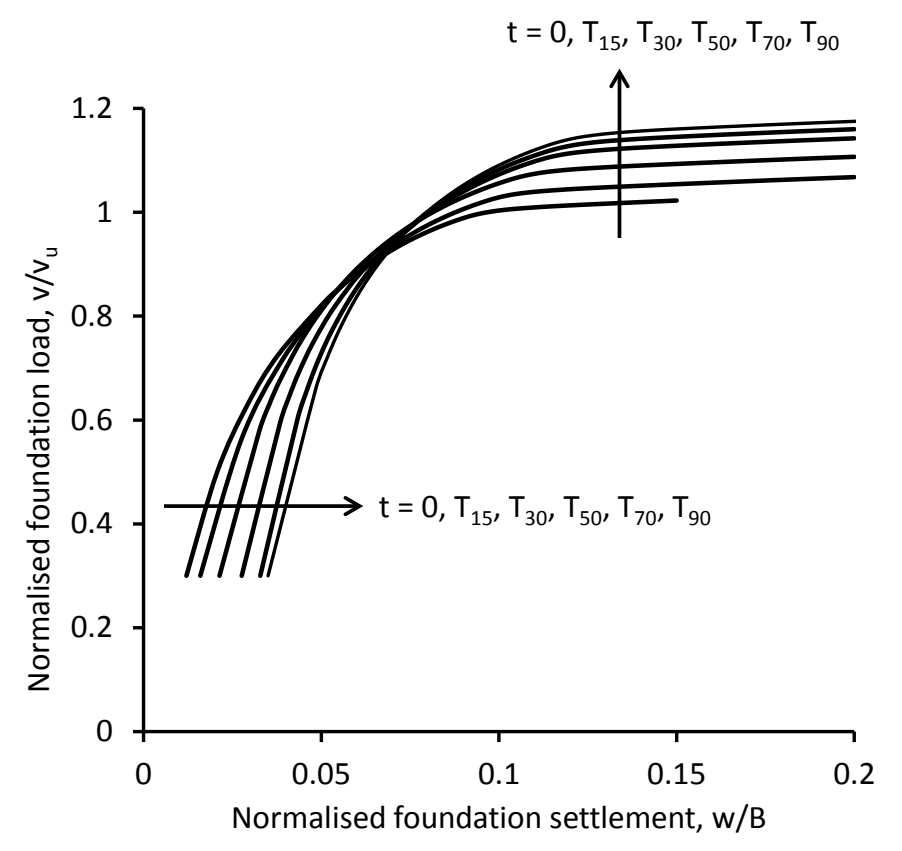

Figure 12. Load-settlement response to failure for a smooth or rough-based strip foundation on normally consolidated deposit under a preload of $0.3 \mathrm{v}_{\mathrm{u}}$ as a function of duration of consolidation 


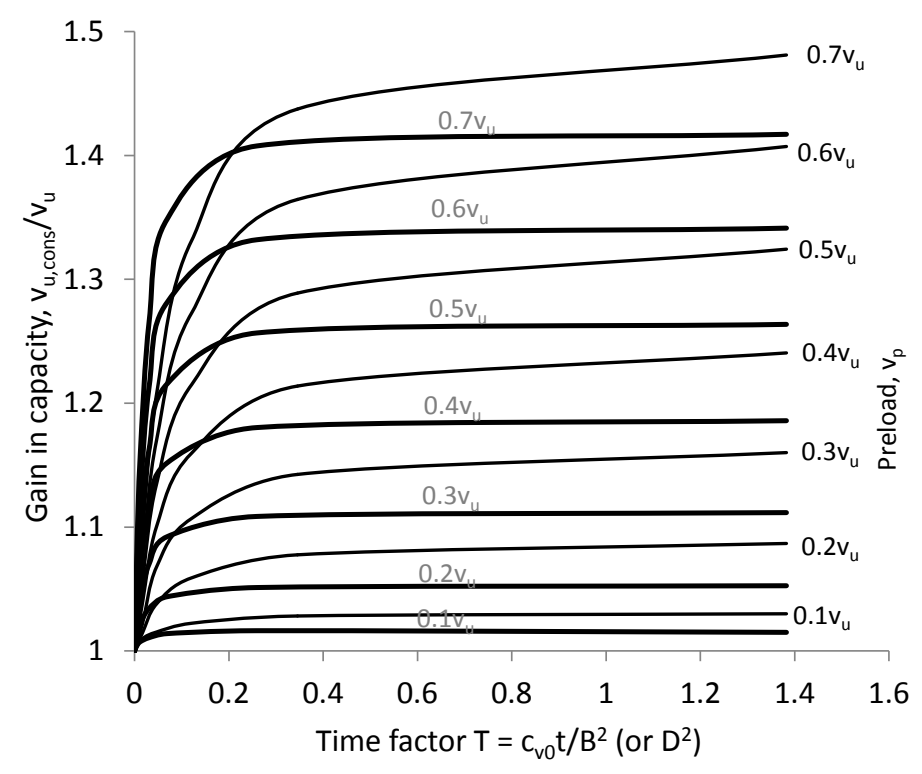

Figure 13. Time-dependent gain in load carrying capacity as a function of preload; smooth or rough-based strip and circular foundations on normally consolidated deposit, OCR = 1

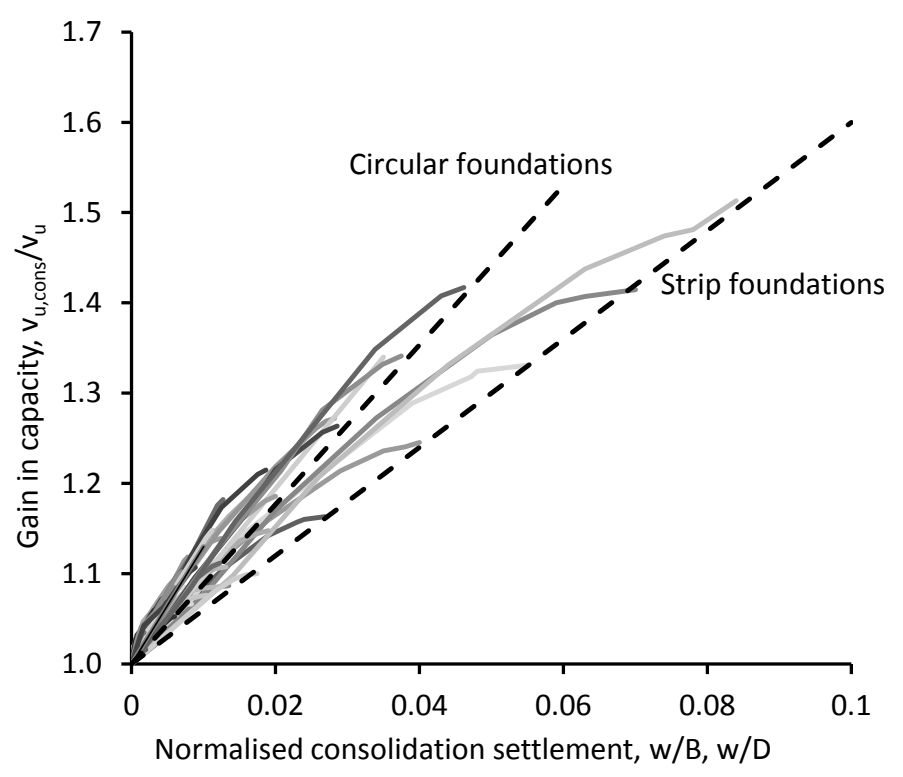

Figure 14. Prediction of gain in bearing capacity from consolidation settlement 


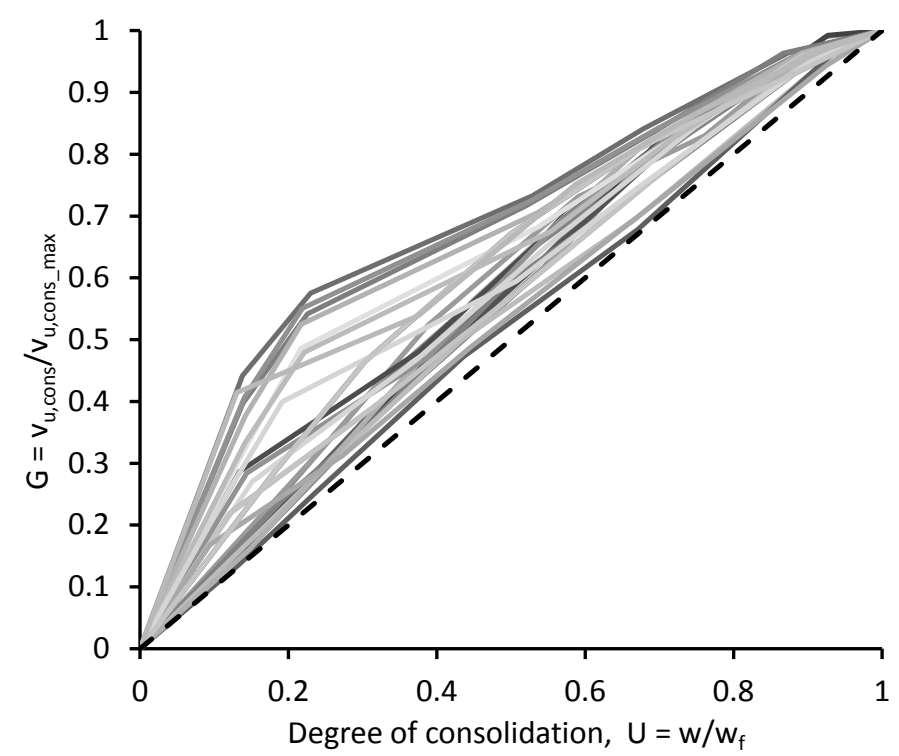

(a)

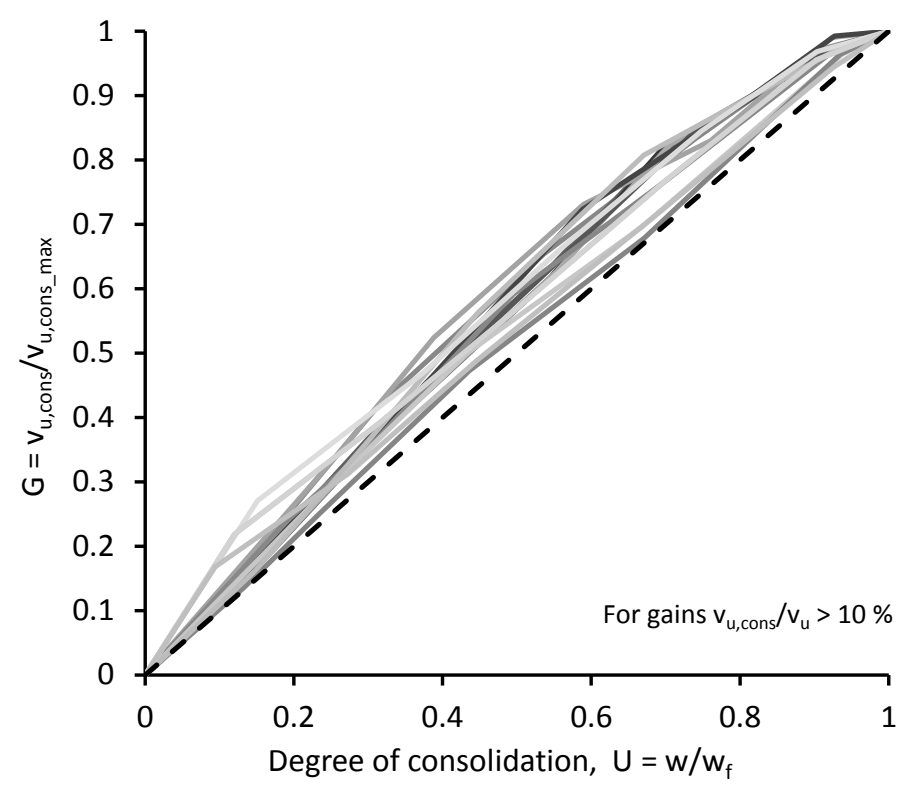

(b)

Figure 15. Hardening rule for prediction of relative gain in bearing capacity as a function of degree of consolidation (a) for all cases and (b) for gains in bearing capacity $>10 \%$ 